\title{
Bourdieu viene a la ciudad: pertinencia, principios, aplicaciones ${ }^{1}$
}

Loüc Wacquant. Universidad de California en Berkeley. Centro de Sociología Europea, París

RESUMEN | Este artículo presenta los temas y contribuciones de la doble sección de "Eventos y debates" llamada "Llevando a Bourdieu a la ciudad". ${ }^{2}$ Primero establezco la pertinencia de la sociología de Bourdieu para los investigadores de la ciudad, revisitando su temprana obra desarrollada en Bearne y Argelia sobre el poder, el espacio y la urbanización, vinculándola a su disección posterior del sufrimiento social en la metrópoli francesa. A continuación, pongo en relieve cuatro principios transversales que animan la práctica investigativa de Bourdieu y que pueden fructíferamente guiar la investigación urbana: (1) el imperativo bachelardiano de la ruptura y la vigilancia epistemológica, (2) el mandato weberiano para efectuar la triple historización del agente (habitus), el mundo (espacio social, del cual el campo es solo un subtipo), y las categorías del analista (reflexividad epistémica), (3) la invitación leibnizianadurkheimiana para desplegar el modo topológico del razonamiento para rastrear las correspondencias mutuas entre el espacio simbólico, el espacio social y el espacio físico, y (4) el momento cassireriano que nos insta a reconocer la eficacia constitutiva de las estructuras simbólicas. También señalo tres trampas que los exploradores bourdianos de la ciudad deben tener especial cuidado para evitar: la fetichización de los conceptos, las seducciones de un "hablar bourdiano" sin realizar las operaciones de investigación que las nociones de Bourdieu estipulan, y la imposición forzada de su marco teórico en bloque cuando se utiliza de forma más productiva en conjunto mediante la transposición.

PAlAbras ClaVe | Bourdieu, ciudad, espacio, topología social, poder simbólico, vigilancia epistemológica, campamento, urbanización, estudios urbanos.

1 Gestionado y traducido por Javier Ruiz-Tagle (Profesor Asistente, Instituto de Estudios Urbanos y Territoriales, Pontificia Universidad Católica de Chile).

2 Nota de la traducción: La sección a la que refiere es un número doble de la revista International Journal of Urban and Regional Research (IJURR), en prensa 2017, del cual este artículo es la nota editorial introductoria. El autor de este artículo, a quien se le agradece por facilitar el texto, tiene los derechos de la obra Bourdieu Comes to Town: Pertinence, Principles, Applications y otorga explícitamente su autorización para traducción y publicación en EURE. 
ABSTRACT | This article introduces the themes and contributions to the double "Events and debates" section on "Taking Bourdieu to Town." I first establish the pertinence of Bourdieu's sociology for students of the city by revisiting his early Béarn and Algerian work on power, space, and urbanization and linking it to his late dissection of social suffering in the French metropolis. Next, I spotlight four transversal principles that animate Bourdieu's research practice and can fruitfully guide urban inquiry: the Bachelardian imperative of epistemological rupture and vigilance, the Weberian command to effect the triple historicization of the agent (habitus), the world (social space, of which field is but a subtype), and the categories of the analyst (epistemic reflexivity); the Leibnizian-Durkheimian invitation to deploy the topological mode of reasoning to track the mutual correspondences between symbolic space, social space, and physical space; the Cassirer moment urging us to recognize the constitutive efficacy of symbolic structures. I also flag three traps that Bourdieusian explorers of the city should exercise special care to avoid: the fetishization of concepts, the seductions of "speaking Bourdieuse" while failing to carry out the research operations Bourdieu's notions stipulate, and the forced imposition of his theoretical framework en bloc when it is more productively used in kit through transposition.

KEYWORDs | Bourdieu, city, space, social topology, symbolic power, epistemological vigilance, camp, urbanization, urban studies 


\section{Bourdieu viene a York, Inglaterra}

En mayo de 2012, una convocatoria internacional de investigadores, que abarcó sociología, antropología, ciencias políticas, geografía y diseño urbano, tuvo lugar en la Universidad de York a partir de una invitación de Mike Savage y de mí mismo para un taller de dos días, copatrocinado por la revista International Journal of Urban and Regional Research (IJURR), destinado a evaluar las perspectivas, los beneficios y las trampas de "Llevando a Bourdieu a la ciudad"; es decir, a traer los conceptos, los métodos y los argumentos distintivos del autor de La Distinción (Bourdieu, 1979) para apoyar directamente la investigación urbana. ${ }^{3}$ La agenda de la reunión fue presentada de la siguiente manera:

$\mathrm{Al}$ inicio del siglo, la ciudad es nuevamente el lugar privilegiado de rápidas innovaciones tecno-económicas, desigualdades sociales resurgentes, marginalidades arraigadas y viciosas divisiones culturales. Estas asumen nuevas y agudas formas, y generan prácticas innovadoras de protesta que requieren enfoques analíticos novedosos. La obra de Pierre Bourdieu es un gran recurso teórico y empírico no explotado para estudiar estas temáticas y para, en el proceso, enriquecer la sociología urbana. Este taller reunirá académicos que han utilizado los conceptos más distinguidos de Bourdieu (habitus, capital, campo, poder simbólico, doxa) para analizar giros de práctica, estructura y política en la ciudad. Ellos harán un balance de sus hallazgos, aclararán las implicaciones de su trabajo y especificarán los méritos y los límites del marco de Bourdieu para el análisis urbano.

La idea para esa reunión surgió después de leer el provocativo y parcial texto The Lost Urban Sociology de Pierre Bourdieu (La sociología urbana perdida de Pierre Bourdieu) de Mike Savage (2011), mientras dictaba mi curso de otońo de 2011, llamado "Metropolis Unbound: Whither Urban Sociology?" (Metrópolis desatada: ¿Adónde va la Sociología Urbana?) en Berkeley. La persistente dificultad para identificar las ramas más pertinentes de Bourdieu para la investigación 'sobre' y 'en' la ciudad, la continua confusión en torno a los orígenes y el propósito de sus construcciones teóricas, junto con la lentamente creciente marea de publicaciones (ahora convertida en tsunami) haciendo invocaciones retóricas de sus conceptos sin ponerlos realmente en práctica $^{4}$, me convenció de que el momento era propicio para llevar a Bourdieu explícitamente hacia los estudios urbanos.

3 El taller se celebró bajo la tutela del Centro de Investigaciones Urbanas (curB) y del Centro Europeo de Exploración Cultural de York (YeCCE), siendo yecCe el que aportó la mayor parte del apoyo financiero. Queremos agradecer a Josine Opmeer y Jack Denham por su invaluable apoyo administrativo, y a todos los presentadores y delegados que hicieron de la conferencia un evento tan estimulante. Estamos agradecidos también de Simon Parker por sus contribuciones en terreno y por su paciente ayuda después en el 'pastoreo' de los artículos a través del proceso de revisión, y a los autores por aceptar pasar por múltiples (y aparentemente interminables) rondas de revisiones.

4 Esto contrastaba fuertemente con la incapacidad de los lectores de mi libro "Urban Outcasts" (Los condenados de la ciudad, incluidos mis propios estudiantes) para percibir los parámetros de una investigación inspirada en Bourdieu, porque su idiolecto conceptual no se muestra expresamente en ella. En media docena de simposios, ni un solo crítico del libro percibió su inspiración y sus implicancias teóricas para repensar el nexo entre el poder simbólico y el espacio físico en la ciudad. 
Esto implicaría tres movimientos complementarios: primero, recuperar su temprana y tardía preocupación empirica por la urbanización y por la dimensión espacial de la dominación, contrario a la historia convencional de que Bourdieu habría "minimizado, y hasta descuidado", este último (Ripoll 2010, p. 365); segundo, explicar el lugar del modo topológico del razonamiento y la trialéctica de espacios simbólicos, sociales y físicos en el corazón de la visión de Bourdieu sobre la sociedad y la historia (Wacquant, 2013); y tercero y más importante, reunir y mostrar el significativo cuerpo de investigación y teorización urbana ya producido por una nueva generación de académicos alrededor del mundo que emplean exitosamente los principios y proposiciones de Bourdieu. ${ }^{5}$ Esto rápidamente llevó a la idea de una conferencia de trabajo diseñada para crear un impulso para este proyecto, que Mike Savage organizó con entusiasmo y generosidad en York en la primavera siguiente, justo antes de su traslado a la London School of Economics.

Al decir de todos, el evento fue enérgico y energizante tanto para los participantes como para la audiencia. El primer día se presentaron cuatro sesiones ampliadas con investigadores que han desplegado a Bourdieu en el frente metropolitano, dedicado al aislamiento territorial y a la espacialización de la desigualdad; migración, etnicidad y precariedad urbana; políticas públicas y la reestructuración del espacio urbano; y dominación simbólica, capital cultural y clases medias urbanas. El segundo día contó con una intensa discusión en torno a artículos más cortos de investigadores jóvenes (incluyendo estudiantes de doctorado) de lugares tan lejanos como Oslo, Los Ángeles, Bristol, Winnipeg, Ámsterdam y París, sobre temas como el poder y el privilegio en la ciudad, privación y desorden en conjuntos de viviendas sociales, métodos para investigar las divisiones comunitarias y culturales, y política metropolitana. Esta doble sección de "Eventos y debates" se basa en una selección de los artículos presentados en York, junto con artículos adicionales reclutados especialmente para ella (de colegas que fueron invitados al evento británico, pero no pudieron asistir debido a problemas de agenda).

Una de las principales virtudes del marco teórico de Bourdieu es su capacidad de abarcar niveles de abstracción y de viajar sin problemas a través de escalas analíticas para vincular grandes estructuras de poder (un país, estado o metrópoli) al nivel meso de las instituciones (tales como campos de producción cultural, ciencia, periodismo y política), hasta las minucias de la interacción cotidiana y la textura fenomenológica de la subjetividad encapsulada por el concepto de 'práctica'. Una

Esto me llevó a escribir un post scríptum reflexivo especificando cómo "Urban outcasts" (Wacquant, 2008) implementa cinco principios analíticos propuestos por Bourdieu (Wacquant, 2015).

5 Esta generación se basa en las obras ejemplares de predecesores que merecen ser destacados desde el principio. Junto con los libros pioneros de Monique y Michel Pinçon (1989, 1992, 2010) a partir de los ańos noventa, mapeando el análisis de Bourdieu sobre clase, poder y cultura en los distritos exclusivos del Gran París (sobre lo cual hay más en adelante), dos estudios extienden valientemente el modelo teórico y la metodología original de La distinción para abarcar la composición espacial de la ciudad: el estudio de Lennard Rosenlund ([2001] 2009) sobre la transformación posindustrial del puerto noruego de Stavanger; y la exploración de Virgilio Pereira (2005) sobre las conexiones entre clase, barrio y sociabilidad en Oporto. Las actividades de la Red Leverhulme sobre Marginalidad Urbana Avanzada (2008-2012) también llevaron las teorías de Bourdieu hacia territorios de relegación en cuatro continentes (véase Wacquant, Slater y Borges-Pereira, 2015). 
segunda característica atractiva de la sociología de Bourdieu es su compromiso permanente de tratar los determinantes materiales y simbólicos, no como causas finales, sino como momentos entretejidos en un análisis que gira sin cesar entre estos dos componentes de la vida social y como recursos que pueden movilizarse, y también convertirse en estrategias sociales. Un tercer elemento es su práctica seductora de politeísmo metodológico que desafía frontalmente la oposición convencional entre técnicas establecidas de investigación, ejemplificadas hoy en día por el abismo adormecedor y la ignorancia mutua entre los estudios cuantitativos del "urbanismo global" y las investigaciones cualitativas de la sociabilidad y la cultura urbana a ras de suelo. ${ }^{6}$

Las contribuciones aquí reunidas ${ }^{7}$ ejemplifican colectivamente estas cualidades. El primer grupo de seis trabajos publicados en este número toma una visión macroscópica desde arriba, basándose en análisis cuantitativos (encuestas y análisis de correspondencias múltiples, la técnica estadística favorecida y fomentada por Bourdieu; véase Lebaron y Leroux, 2016) y el seguimiento de estrategias de protagonistas clave 'en' y 'sobre' el campo del poder para iluminar la producción y reproducción de la desigualdad urbana, y el cambio a nivel estructural a través de la creación de categorías de percepción espacial, formas distintivamente urbanas de capital cultural, y estrategias de clase de control sobre el lugar y el hogar. Un segundo grupo de artículos que continuarán este número [de IJURR] migrará hacia abajo de la estructura de clase y urbana para ofrecer una visión microscópica complementaria desde abajo, basándose en la observación etnográfica y entrevistas en profundidad para llevar cabalmente al lector hacia el tejido cognitivo, emocional, estético, religioso, criminal y político de la existencia ordinaria en La Paz, Estambul, Buenos Aires, las viviendas sociales de la periferia parisina, una villa miseria argentina, una pequeńa ciudad de Dinamarca, y un rincón violento del centro de Filadelfia.

\section{La pertinencia urbana de Bourdieu: una breve digresión juvenil}

Este no es el lugar para recorrer los voluminosos escritos de Bourdieu (unos 37 libros y alrededor de 400 artículos) a fin de extraer una recapitulación completa de sus investigaciones directas o indirectas acerca de las formas y fuerzas urbanas a lo largo de las cuatro décadas de su prolífica vida científica. Pero es útil establecer la pertinencia básica del sociólogo francés en las agendas clásicas y contemporáneas de los investigadores urbanos, para así centrarse en un conjunto poco conocido de estudios vinculados que abordan la urbanización oblicuamente; a saber, sus primeros escritos

Estas tres características se presentan mejor en The State Nobility (La nobleza del Estado, Bourdieu, 1989), que combina observación etnográfica y entrevistas, prosopografía e información de archivo, y análisis cuantitativos para rastrear la conversión mutua de estructuras sociales y mentales en múltiples escalas, desde las experiencias ordinarias y estrategias académicas de los estudiantes de escuelas de elite, a la correspondencia estructural entre el campo económico y el campo del poder, a la invención histórica del estado burocrático asociado al surgimiento del capital cultural.

$7 \quad$ Nota de la traducción: Aquí el autor se refiere a los artículos reunidos en los números especiales de la revista International Journal of Urban and Regional Research (IJURR), en prensa 2017. 
sobre trastornos sociales, ruptura cultural, y formación del sujeto en la Argelia colonial y la Francia rural. ${ }^{8}$

En una serie de largos artículos y tres libros (algunos solo y otros coescritos con su estudiante y asistente de campo de Cabilia, Adbelmalek Sayad, y con un grupo de matemáticos de la oficina francesa de estadística con sede en Argel), publicados entre 1958 y 1964, el joven Bourdieu disecciona las contradicciones y conflictos que devastan la sociedad colonial de Argelia, donde había sido enviado para cumplir su servicio militar, y la crisis de la sociedad campesina de Bearne, una remota región rural de los Pirineos donde se había criado antes de trasladarse a París para su educación universitaria. ${ }^{9}$ En ambos sitios, la urbanización es el vector y la expresión clave de la transformación social, y la ciudad, el pueblo, o el campamento, el sitio que ancla y materializa las fuerzas que disuelven el tejido social del campo francés, por un lado, y que derriba el imperialismo francés en el norte de África, por el otro.

Basado en un estudio sobre patrones de matrimonio en su poblado de la infancia, que combina historia social, estadísticas y etnografía, Bourdieu muestra cómo la situación económica y social influye en las tasas crecientes de soltería en una sociedad campesina basada en la primogenitura, mediante la mediación de la conciencia corporeizada que los hombres adquieren desde esta posición. La escena de un baile de sábado al margen del cual los solteros locales se reúnen sin bailar sirve para diseccionar la colisión cultural entre campo y ciudad, y la consiguiente devaluación de los hombres del poblado a medida que las categorías urbanas de juicio penetran en el mundo rural:

Este pequeño baile de campo es el escenario de un verdadero choque de civilizaciones. A través de él, el mundo de lo urbano, con sus modelos culturales, su música, sus danzas, sus técnicas del cuerpo, irrumpe en la vida campesina. Los patrones tradicionales de comportamiento festivo se han perdido o han sido reemplazados por patrones urbanos. Tanto en esta esfera como en otras, la iniciativa le pertenece a la gente de la ciudad (bourg). (Bourdieu [1962], 2002, p. 582)

La exploración — con métodos mixtos de Bourdieu a lo ancho del Mediterráneo sobre la muerte de la sociedad rural en la Cabilia imperial y su región natal de Bearne es la matriz empírica y emocional que genera su preocupación epicentral por la dialéctica de las estructuras sociales y mentales, su descubrimiento de la especificidad de las prácticas lógicas, y su concepción pragmática de la reflexividad epistémica. También refuta el mito académico de Bourdieu como "el teórico de la reproducción”, revelándolo como un astuto analista de la transformación histórica, la disyunción cultural y la fisura de la conciencia (Wacquant, 2004), tres propiedades que son esencialmente urbanas.

9 Estas publicaciones son: el fluido artículo de 1962 sobre "Bachelordhood and the Peasant Condition" [la soltería y la condición campesina], más tarde incorporado en "The Ball of Bachelors" [El baile de los solteros] (Bourdieu, 2002); la monografía de 1958 "Sociology of Algeria" [Sociología de Argelia] (traducida al inglés en una versión renovada como "The Argelians" [Los argelinos], 1962); el par de estudios "The Uprooting: The Crisis of Algerian Agriculture” [El desarraigo: la crisis de la agricultura argelina] (Bourdieu \& Sayad, 1964) y "Work and Workers in Algeria” [El trabajo y los trabajadores en Argelia] (Bourdieu et al., 1963); y una serie de artículos recolectados póstumamente como "Algerian Sketches" [Bocetos argelinos] (Bourdieu, 2008). Para localizar y vincular estas investigaciones, véase el número especial de la revista Etnography sobre "Pierre Bourdieu in the Field" [Pierre Bourdieu en el campo] (vol. 5, n. ${ }^{\circ} 4$, diciembre de 2005). 
Debido a que su educación y posición en la división del trabajo por género las llevan a ser sensibles a la "tenue" [equipo] (vestimenta, postura, conducta) y además abiertas a los ideales de la ciudad, lo que para ellas representa la emancipación, las mujeres jóvenes asimilan los patrones culturales de la ciudad más rápido que los hombres; esto condena a estos últimos a ser medidos por varas que los hacen inútiles a ojos de posibles compañeras de matrimonio. A medida que el campesino internaliza la imagen devaluada que otros forman de él a través del prisma de las categorías urbanas, llega a percibir su propio cuerpo como "empobrecido", cargado por las huellas de las actividades y actitudes asociadas con la vida agrícola. La miserable conciencia que construye de su cuerpo lo lleva a adoptar una actitud introvertida que amplifica la timidez y la tosquedad producidas por las relaciones sociales marcadas por la extrema segregación entre los sexos y la represión del intercambio de emociones. Las tasas decrecientes de sindicatos que se derivan de lo anterior desbaratan el sistema de estrategias de reproducción social y condenan a la sociedad campesina a "una crisis mortal" (Bourdieu [1962], 2002, p. 126).

En este estudio, la ciudad emerge como el lugar invisible de la escuela, los medios de comunicación y las ocupaciones comerciales, es decir, instituciones cuya atracción magnética y estímulos distantes fomentan la "apertura" del espacio social y simbólico local. Como resultado, "la oposición entre el urbanita de la ciudad y el campesino de los poblados" viene a suplantar la oposición entre el hijo mayor y sus hermanos menores, entre obreros y sirvientes, y entre grandes y pequeñas familias terratenientes (Bourdieu [1962] 2002, pp. 67, 75), y gradualmente sella todos los lazos sociales y jerarquías culturales. ${ }^{10}$ Bourdieu mapea la distribución geográfica cambiante de las personas, las ocupaciones y las actividades a lo largo de medio siglo, así como la organización espacial del hogar, para revelar cómo "la oposición entre el campesino y el urbanita surge en el corazón mismo de la comunidad del poblado" Bourdieu [1962] 2002, p. 97) y lo socava desde dentro. Sigue la intensidad y la direccionalidad de los flujos matrimoniales entre los poblados y la ciudad por distancia geográfica entre parejas y descubre que la proporción de "matrimonios exteriores" aumenta con el tiempo a medida que los residentes de la ciudad se alejan de los poblados para buscar pareja en otras ciudades y metrópolis. Se deduce que "la distancia social impone limitaciones mucho más estrictas que la distancia espacial. Los circuitos de los intercambios matrimoniales se separan de su base geográfica para organizarse en torno a nuevas unidades sociales definidas por el intercambio de condiciones de existencia y estilos de vida específicos" (Bourdieu [1962], 2002, p. $85)$. En otras palabras, las fuerzas urbanas hacen que el espacio social se autonomice del espacio físico a través de la difusión de constructos mentales generados por la ciudad —o que el Bourdieu maduro ([1992] 2002, p. 119) llamará más tarde "la unificación del mercado de bienes simbólicos". Además, sus efectos se extienden mucho más allá de los límites de la ciudad, lo que la sociología urbana ingenuamente toma como frontera de su dominio empírico.

10 La asimetría socio-simbólica entre la ciudad y el campo es capturada en esta concisa observación: "Mientras que un nativo del poblado nunca, en circunstancias ordinarias, sueña con ir a un baile en una ciudad cercana, los urbanitas vienen a menudo en grupos a los bailes campestres, donde su atractivo urbano les da una considerable ventaja sobre los campesinos" (Bourdieu [1962] 2002, p. 84). 
Cruzando el Mediterráneo, encontramos al joven Bourdieu examinando los dos lados del cambio cataclísmico de la colonia francesa de Argelia atrapada en la agonía de la sangrienta guerra de independencia (1954-1962), que se basaba en el control violento tanto de los espacios rurales como de los urbanos. En Le Déracinement (The Uprooting [El desarraigo], Bourdieu y Sayad (1964), y también en Bourdieu (1958, cap. 6), el filósofo francés vuelto sociólogo junta encuestas y etnografías para trazar la destrucción del campesinado nativo y su modo de producción doméstica basado en el parentesco y el honor, a través de la expoliación de tierras, la mercantilización de los cultivos fomentada por el desarrollo de los mercados urbanos y el desplazamiento forzado y reasentamiento de millones de fella ${ }^{11} .{ }^{12}$ La masiva transferencia de población impuesta por los militares franceses, en un intento desesperado de socavar el apoyo al levantamiento nacionalista, generó dos constelaciones urbanas distintivas: campamentos controlados por militares, y barriadas que proliferaron en las principales ciudades de la colonia. Travail et Travailleurs en Algérie (Work and Workers in Algeria [El trabajo y los trabajadores en Argelia] Bourdieu et al., 1963) recoge la historia del lado urbano para documentar la formación custodiada de la clase obrera, reunida en los extensos distritos populares y viviendas sociales de Argel. Se profundiza en la dialéctica de las "estructuras económicas y estructuras temporales" para rastrear la forma en que los antiguos campesinos vienen a adquirir (o no) los esquemas mentales necesarios para participar en la economía capitalista y para navegar por la desconcertante escena social de la ciudad, incluyendo el "espíritu de cálculo" que fomenta la "racionalización de la conducta" característica de la urbanidad moderna.

Desde estos estudios gemelos, aprendemos que el control y la delimitación del espacio y de los asentamientos son epicentrales tanto para la imposición del poder colonial como para la resistencia indígena (involucrando tanto a los beréberes contra los árabes como a los argelinos contra los franceses) y que la apropiación de la vivienda en la ciudad es fundamental para la reestructuración de la economía material y moral de la familia. De hecho, la posición en el mercado del trabajo y el acceso diferencial a la vivienda alimentan conjuntamente la divergencia entre una clase obrera estable que apoya la revolución nacionalista y un subproletariado flotante atraído por el milenarismo (Bourdieu, 1977). Pero, sorprendentemente, es la meticulosa sociografía de la creación, estructura y funcionamiento de los campamentos de campesinos desplazados la que ofrece el modelo más claro de la sociología urbana de Bourdieu. Esto porque el campamento es una formación protourbana y antiurbana a la vez: por un lado, devalúa las formas habituales de ser, pensar y sentir de las poblaciones rurales reubicadas y funciona como cámara de aclimatación para los modelos culturales y relaciones sociales de la ciudad; y por otro lado, frena la urbanización, ya que priva a sus ocupantes de los recursos, incluidos el espacio y el tiempo, necesarios para adaptarse a su condición suspendida, mientras que revuelve

11 Nota de la traducción: fellah es el nombre que reciben los campesinos del norte de África.

12 En 1960, unos 2,1 millones de argelinos habían sido reubicados forzosamente en campos militarizados, mientras que los inmigrantes en las ciudades llegaban a otro millón. Juntos representaban por lo menos la mitad de la población total de origen rural, haciendo de este "desplazamiento de población uno de los más brutales conocido en la historia” (Bourdieu \& Sayad, 1964, p. 13). 
los principios de visión y división social. Como una formación socioespacial artificial nacida de la coerción, el campamento ofrece un experimento social acelerado y extremo en lo que Bourdieu bautiza como "urbanización real y ficticia".

Vale la pena recapitular aquí el capítulo "Urbanitas sin ciudades" de El Desarraigo, ya que deshace la "interdependencia que une la estructura de la organización del espacio, la estructura de los grupos sociales y el tipo de sociabilidad" (Bourdieu \& Sayad 1964, p. 118). La aglomeración repentina a través de la reubicación forzosa gatilla una "transformación brutal y total" de "todos los niveles de realidad social". El mayor volumen, densidad y heterogeneidad de los asentamientos —la definición clásica de Louis Wirth [1938] de "El urbanismo como modo de vida"—, determina un cierre de la distancia social entre los grupos establecidos (tribus y linajes) y un cambio rápido en la organización social desde el clan a la familia nuclear. Las nuevas unidades de vivienda autónomas para familias individuales "acentúan y aceleran el debilitamiento de los lazos de parentesco" y fomentan "el surgimiento de solidaridades basadas en la vecindad y sobre todo en la similitud de las condiciones de existencia” (Bourdieu \& Sayad, 1964, pp. 119, 121). Residir en el conjunto compacto efectivamente "rompe el grupo" dispersando a sus miembros y aumenta el "contagio cultural" al alimentar "la confrontación de las diferencias" y al "ampliar la conciencia y el conocimiento del mundo" (ibíd., p. 123). Al crear "un campo social de tipo urbano" (ibíd., p. 132) donde el anonimato reemplaza a la familiaridad mutua, el campamento fomenta el surgimiento de un nuevo tipo de sociabilidad, simbolizada por la cafetería y la difusión del velo entre las mujeres en respuesta a la superposición disruptiva entre espacios masculinos y femeninos. La solidaridad "inspirada en imperativos habituales" y en "el sentimiento de hermandad" es sustituida por "la solidaridad de la miseria impuesta por la promiscuidad” (ibíd., pp. 136-137).

En la "situación cuasiurbana" del campamento, los modelos dominantes de comportamiento y consumo son los de la ciudad — al campamento se le llama blad, la palabra beréber para la ciudad-. Estos modelos "devalúan las virtudes campesinas, en adelante inútiles y fuera de lugar", socavan la edad como fundamento de la autoridad y "llevan a cabo una inversión de las jerarquías tradicionales" (ibíd., p. 141) en beneficio de aquellos linajes más familiarizados con las actividades, ocupaciones y normas urbanas. Además,

la ruptura con el viejo ambiente y con las rutinas que solían asociarse a él, la ampliación del campo de las relaciones sociales, la estructura misma del espacio habitado, sea el asentamiento o el hogar, incitan comportamientos urbanos y suscitan inquietudes, intereses, y aspiraciones que son las del urbanita. (Ibíd., p. 142)

Esto es testimoniado, por ejemplo, en el rápido cambio en los perfiles de consumo (asistencia a cafeterías, gastos médicos y tabaquismo aumentan espectacularmente), la vestimenta (los peinados tradicionales son abandonados, la corbata es adoptada y el velo hace su aparición), y la adquisición de una plétora de nuevos objetos domésticos (camas de metal, armarios, tarros y platos de lata, etcétera). ${ }^{13}$ En el campa-

13 El fino análisis estadístico de los cambios en los presupuestos y hábitos alimentarios por ubicación y ocupación (Bourdieu \& Sayad 1964, pp. 144-149) es una notable prefiguración del capítulo de La distinción sobre el gusto y perfiles alimentarios de clase (Bourdieu, 1979). 
mento, los ingresos y la riqueza ya no están dedicados a mantener relaciones de parentesco y valores campesinos colectivos. Por el contrario, "los nuevos ricos de hoy, cuya riqueza rara vez proviene de la tierra, se esfuerzan por imitar a los habitantes urbanos y marcar por todos los medios posibles su distancia de los campesinos" (ibíd., p. 143). El individualismo estratégico y la anomia cultural crecen al unísono:

Debido a la dispersión de unidades sociales, el aflojamiento de lazos sociales tradicionales, y el debilitamiento del control de la opinión, la transgresión de la regla tiende a convertirse en la regla; nada impide el individualismo introducido por la economía moderna. Dentro del reasentamiento, como enormes y dispares agregados de individuos aislados, cada uno se siente protegido por su anonimato; todos se sienten responsables de sí mismos, pero solo de sí mismos y por sí mismos. (Ibíd., pp. 149-150)

La protourbanización forzada también desencadena una transformación del perfil emocional de la vida cotidiana: se establece una "melancolía colectiva", que "revela desesperación y ansiedad”. Reveladoramente, los residentes del campamento de Kerkera usan tres modismos para expresar su sensación de estar atrapados en un espacio adverso: la prisión, la desnudez y la oscuridad de la noche (que recuerda el lenguaje de los reclusos en los campos de concentración nazis). ${ }^{14}$ Esto, ya que todo en la organización de su entorno construido, desde la "uniformidad funcional de las viviendas estandarizadas" hasta la disposición interna de las viviendas (desprovisto de patios, rejas y aberturas), la ubicación reglamentada de tiendas y fuentes, hasta la amplitud y orientación de las calles, "decepciona y contradice las expectativas" traídas del campo (ibíd., p. 152). Esto es más detectable en el "lenguaje corporal" y en los patrones de circulación de los residentes del campamento: en vez de tomar la ruta más rápida entre dos puntos, los hombres hacen rodeos y caminan furtivamente a lo largo de las paredes, mientras las mujeres permanecen encerradas porque ya no disfrutan la protección de los espacios femeninos exclusivos.

Por último, "al revocar la organización del espacio vital, lugar de acción técnica y ritual, el reasentamiento altera los ritmos temporales asociados a él” y, de hecho, "impacta toda la experiencia de la temporalidad" (ibíd., p. 156). En el campamento, los fellah y sus familiares descubren la concepción capitalista del trabajo y con ella la noción del tiempo como un bien escaso, susceptible de ser ahorrado, gastado o desperdiciado. Se someten a nuevos ritmos establecidos por los toques de queda, las horas de apertura y cierre de las escuelas, las oficinas burocráticas, la clínica y la fuente, y por el aumento de la duración de los viajes. El tiempo es ahora tallado y estampado, no por actividades tradicionales (como las cinco oraciones del día, que sincronizan a todos), sino por las campanas periódicas y los timbres telefónicos regulares de la torre de control. En todos los frentes, las mismas oposiciones sociales y simbólicas entre el

14 La desorientación subjetiva de los residentes del campamento proviene de la disyunción entre sus disposiciones adquiridas y el espacio en el que se ven obligados a evolucionar: "Porque todo su habitus corpóreo es 'hecho' por y para el espacio de sus movimientos habituales, el campesino desarraigado es golpeado en su ser más íntimo, tan profundamente que no puede articular su desorden y aún menos definir su razón” (Bourdieu \& Sayad, 1964, p. 152). 
campesino y el urbanita (como Bourdieu detectó en Bearne) cristalizan en el campamento para acelerar la disolución de la sociedad rural de Cabilia.

Esta recapitulación compacta de las investigaciones jóvenes e intermediterráneas de Bourdieu acerca de la contradicción y el cambio en la Bearne provincial y la Argelia colonial demuestra la pertinencia directa de su trabajo para el centro de la sociología urbana. Estas obras no solo abordan el nexo de poder, espacio y urbanización en dos sociedades, sino también desde la perspectiva de sus áreas rurales. Las obras establecen que todas las estructuras sociales y mentales tienen correlatos espaciales y condiciones de posibilidad; que la distancia social y las relaciones de poder están expresadas en y reforzadas por la distancia espacial; y que la cercanía al centro de acumulación de capital (económico, militar o cultural) es un determinante clave de la fuerza y la velocidad del cambio social. De hecho, estos primeros estudios sugieren que el poder estatal (colonial en Argelia, central en Francia) se ejerce a través del control y la penetración del espacio, la organización de asentamientos (a través de procesos complementarios de concentración y dispersión), la distribución geográfica de autoridades simbólicas y la regulación de la movilidad física, según la fórmula rudimentaria:

poder $\rightarrow$ espacio físico $\rightarrow$ estructura y relaciones sociales $\rightarrow$ práctica y subjetividad

(incluyendo la composición del yo, las aspiraciones, las emociones y el sentido del tiempo). ${ }^{15}$ Además, retratan la ciudad como un ambiente social distintivo, caracterizado por una diferenciación social y funcional acelerada, el desanclaje del simbolismo desde las relaciones ordinarias que fomentan la elaboración e innovación cultural, la difusión del anonimato y la individualidad, la creciente heterogeneidad interna y dispersión de habitus, y la rutinaria desalineación de posiciones y disposiciones. En pocas palabras, los estudios jóvenes de Bourdieu sobre Bearne y Argelia constituyen su verdadera "sociología urbana perdida" y el más rico acervo de observaciones e hipótesis que ha ofrecido a los estudiosos de la estructura y la experiencia social en la ciudad.

Otra de las virtudes de estas ignoradas publicaciones de principios de los años sesenta es que revelan la base olvidada de la problemática general de la proyecciónconversión mutua del espacio simbólico, espacio social y espacio físico a través de luchas por la apropiación y delimitación del entorno construido que Bourdieu articularía en su obra sobre el sufrimiento social en la metrópoli tres décadas más tarde. En 1990, Bourdieu recibió fondos de la Caisse des Dépots et Consignations de Francia (la institución financiera estatal encargada de fomentar el desarrollo económico y la

15 El hecho de que la cadena causal es iniciada por el poder es claro desde el principio de The Uprooting [El desarraigo]: "Argelia era el sitio experimental en el que la mente militar imprimía sus estructuras, como en una prueba proyectiva" (Bourdieu \& Sayad, 1964, pp. 26-27), "el disciplinamiento del espacio" sirviendo de vehículo para "el disciplinamiento de la población”. En su recapitulación de la penetración de colonos, Bourdieu (1958, p. 106) subraya que la colonización se apoya en "interrupciones deliberadamente y metódicamente producidas para asegurar el control por parte del poder dominante", y él apunta a la captura de la tierra como el "instrumento para la desintegración de las estructuras fundamentales de la economía y la sociedad [nativa]”. 
construcción de viviendas de bajos ingresos) para producir un diagnóstico sociológico acerca de la profundización del malestar en la periferia urbana del país, la cual había escalado al rango de problema nacional supremo a raíz de repetidos disturbios callejeros (Jazouli, 1992). Para articular los parámetros del trabajo de campo del equipo, que eventualmente se convertiría en el libro colectivo The Weight of the World [La miseria del mundo] (Bourdieu et al., 1993), Bourdieu acordó juntarse con William Julius Wilson para copresidir una conferencia internacional sobre "Pobreza, Inmigración y Marginalidad Urbana en las Sociedades Avanzadas" que tuvo lugar en la Maison Suger en París en mayo de 1991. ${ }^{16}$ En esa ocasión, presentó un documento de trabajo titulado "Espacio Social y la Génesis del Espacio Físico Apropiado", que abre y enmarca la actual sección de "Eventos y Debates" sobre "Llevando a Bourdieu a la ciudad" (Bourdieu [1991] 2017). ${ }^{17}$ En este texto, que en parte se convertiría en el capítulo dedicado a "Site Effects" ["Efectos de Lugar"] en The Weight of the World" [La miseria del mundo] (Bourdieu, 1993), el sociólogo francés advierte en contra de la fetichización del espacio y formula a un nivel abstracto las relaciones entre espacio social y espacio físico que se manifestaron concretamente en los estudios de Bearne y Argelia. Pero, ¿cómo implementar esta agenda analítica? Para responder esta pregunta debemos recurrir a los principios de la práctica investigativa que Bourdieu invita a los investigadores de la ciudad a adoptar.

\section{Principios transversales para poner a Bourdieu a trabajar}

Hay muchas maneras de "partir y picar" a Bourdieu para su uso en cualquier dominio de investigación y ya existen varias introducciones estandarizadas y reseñas rutinarias de sus escritos principales destinados a investigadores del espacio y la ciudad (por ejemplo, Painter ,2000; Cresswell, 2002; Webster, 2010; Foggle, 2011; Lippuner, 2012).$^{18}$ Yo mismo entregué una discusión detallada sobre cómo desplegar y distribuir el habitus, el espacio social, el campo burocrático y el poder simbólico en una investigación comparativa del nexo triádico entre marginalidad, etnicidad y penalidad (Marginality, Ethnicity and Penality in the Neoliberal City [Marginalidad, etnicidad y penalidad en la ciudad neoliberal], Wacquant, 2014). En dicho texto esbocé una cartografía de la división analítica del trabajo entre estos conceptos e

16 Yo organicé esta conferencia de trabajo financiada por la Russell Sage Foundation y la Maison des Sciences de l'Homme. Aparte de mis dos mentores, Bourdieu y Wilson, participaron Philippe Bourgois, Alejandro Paul Osterman, Alejandro Portes, Saskia Sassen, Roger Waldinger, Margaret Weir y varios miembros del Centro de Sociología Europea, entre ellos Abdelmalek Sayad. Durante este período, Bourdieu se involucró mucho con las agencias que administran la nueva "política de la ciudad” de Francia. En 1993, cuando el Collège de France recibió un pequeño castillo situado en el anillo exterior de París por medio de una donación benéfica, consideró seriamente la creación allí de un Centro de Investigación sobre la Ciudad.

17 Nota de la traducción: número doble de la revista International Journal of Urban and Regional Research (IJURR), en prensa 2017.

18 Estas cápsulas pedagógicas de sus principales teorías (siempre limitadas a algunas publicaciones importantes traducidas al idioma propio del autor) típicamente pasan por alto la mayoría del corpus de Bourdieu, sufren de prejuicios y cegueras disciplinarias previsibles, y apenas indican cómo traducir estas teorías en diseños y operaciones prácticas de investigación. 
indiqué cómo pueden servir para forjar otros nuevos. Aquí quiero destacar cuatro principios transversales que sustentan y animan la práctica investigativa de Bourdieu; los mismos que el lector apresurado puede pasar por alto, pero que pueden guiar la investigación urbana más fructíferamente que la exégesis de uno u otro escrito. Para efectos de compresión mnemotécnica, adjunto estos principios a cinco autores que forman los pilares centrales del pensamiento de Bourdieu: Bachelard, Weber, Leibniz y Durkheim, y Cassirer. ${ }^{19}$ También señalo tres trampas correlativas que los exploradores bourdianos de la ciudad deberían tener cuidado especial para evitar: la fetichización de conceptos (que detiene la investigación donde debería comenzar), las seducciones de un "hablar bourdiano" solo porque es el lenguaje académico de la época, y la imposición forzada de su marco teórico en bloque cuando se utiliza de manera más productiva en conjunto mediante la transposición.

1. El momento de Bachelard: romper con el sentido común (que viene en tres variedades: ordinario, político y académico) para cuestionar categorías de análisis aceptadas, deconstruir problemáticas prefabricadas y forjar robustos conceptos analíticos, diseñados por y para el análisis empírico, que abarcan — pero se apartan claramente de- nociones coloquiales (Wacquant, 2002). Esta es una aplicación directa del imperativo de ruptura y vigilancia epistemológica, la principal enseñanza de la "epistemología histórica", la filosofía de la ciencia desarrollada por los mentores de Bourdieu, Gaston Bachelard y Georges Canguilhem, que Bourdieu trasplantó de las ciencias naturales y ciencias de la vida a las ciencias sociales (Bourdieu et al., 1968; Bourdieu, 2001; véase Rheinberger, 2010 para un perfil compacto de esta corriente). Este es un momento de indagación a menudo ignorado u omitido por rutina: vastos sectores de la investigación urbana aceptan la terminología, las preguntas y las preocupaciones planteadas por administradores locales, tomadores de decisión, periodistas o la moda académica, cuando deberían en cambio detectar y neutralizar el inconsciente histórico y los sesgos sociales incorporados en ellos mismos al incluir estos actores en su objeto de análisis. Como Bachelard (1934, p. 26) advierte: "La mente científica nos prohíbe tener una opinión sobre las preguntas que no entendemos, sobre cuestiones que no sabemos formular claramente. Sobre todo, uno debe saber cómo plantear problemas".

2. El momento de Weber: llevar a cabo la triple historización del agente (con el concepto de habitus), el mundo (a través de la noción de espacio social, del cual el 'campo' no es más que un subtipo), y las categorías y métodos del analista (reflexividad epistémica). Este principio expresa la visión radicalmente historicista y agonística de acción social, estructura y conocimiento de Bourdieu, que es más pertinente en espíritu y método a la obra de Max Weber —aun cuando este último se aferró a un individualismo analítico completamente ajeno al relacionalismo de Bourdieu (Bourdieu, [2000] 2011) —. Para ambos autores, la

19 El hecho de que estos no sean "los sospechosos de siempre" mencionados en las presentaciones estándar de Bourdieu es indicativo de la adormecedora brecha entre la inspiración real y la composición interna de su obra y su imagen académica, formada por capas acumuladas de décadas de lecturas truncadas o mistificadas. 
dominación impregna la vida social, pero adopta una multiplicidad de formas que son irreductibles a alguna base económica y siempre implican la intercesión de una autoridad simbólica que enmarca la relación en cuestión, lo que lleva a Weber (1958) a centrarse en la legitimidad y a Bourdieu en la producción social de la doxa. ${ }^{20}$ En consecuencia, uno debería entender las constelaciones, categorías y prácticas urbanas como los productos, armas y apuestas de las luchas emprendidas sobre múltiples temporalidades, que van desde el largo plazo de las macroestructuras seculares, a los ritmos de nivel medio de los ciclos políticos y los giros institucionales, hasta el cortoplacista horizonte fenomenológico de las personas a ras de suelo. Este mandamiento desmiente la viciada historia académica de Bourdieu como "el teórico de la reproducción", que continúa siendo circulada incluso por académicos urbanos que simpatizan con su enfoque (por ejemplo, Harding y Blokland 2014, pp. 129-130), y captura precisamente tanto sus instrucciones explícitas como su práctica científica existente (Bourdieu \& Wacquant, 1992; Wacquant 2017a).

3. El momento leibniziano-durkheimiano: desplegar el modo topológico de razonamiento para rastrear las correspondencias, transposiciones y distorsiones mutuas entre el espacio simbólico (la trama de clasificaciones mentales que guían a las personas en su construcción cognitiva y conativa del mundo), el espacio social (la distribución fluctuante de activos o capitales socialmente efectivos), y el espacio físico (el entorno construido resultante de esfuerzos en competencia para apropiarse de bienes materiales e ideales dentro y por medio del espacio). Esta forma de pensar es indispensable porque "el espacio social tiende a retraducirse, de una manera más o menos deformada, bajo el disfraz de un ordenamiento definido de agentes y propiedades. Se deduce que todas las divisiones y distinciones del espacio social (alto / bajo, izquierda / derecha, etc.) se expresan de manera real y simbólica en el espacio físico apropiado como espacio social reificado" (Bourdieu, 1997, p. 162). Este principio está en la confluencia del componente geométrico del pensamiento de Bourdieu, basado en su ávida lectura temprana de Gottfried Wilhelm Leibniz (cuyo análisis situs [topología], desarrollado en reacción a la geometría perspectiva de Pascal, ejemplifica el racionalismo monista que Bourdieu desea extender ${ }^{21}$ y su línea morfológica, derivada de la audaz formulación de Durkheim y Mauss (1901) sobre la correspondencia entre el

20 Por eso es Weber y no Marx el ancla de Bourdieu aquí (a pesar del enfoque histórico y relacional de este último): tal como el autor de Wirtschaft und Gesellschaft [Economía y Sociedad], Bourdieu rechaza el determinismo económico, la búsqueda de fundamentos, y la noción neohegeliana de que la historia está dotada de una lógica direccional. Se posiciona de lleno en el linaje neokantiano que considera la filosofía como un deber para comenzar y terminar con "el hecho de la ciencia" y emplea una concepción genética del conocimiento como un proceso sintético perpetuamente inacabado (esta visión anti-metafísica de Kant fue consagrada por la Escuela de Marburgo, donde Cassirer fue formado por Georg Simmel, y que influenció a Weber a través de las obras de Windelband y Rickert, líderes de la escuela rival de neokantianos de Baden).

21 Weik (2010) tiene razón al señalar las similitudes y afinidades entre Leibniz y Bourdieu: la fuerza creadora que constituye el mundo es Dios para el primero y la historia misma para el segundo. Pero él se centra principalmente en el habitus cuando los vínculos más fuertes entre los dos pensadores es su filosofía relacional común del espacio (véase De Risi, 2007, sobre la visión 
sustrato físico y la disposición de grupos sociales, y las "formas de clasificación" a través de las cuales se ven a sí mismos y al mundo.

4. El momento de Cassirer: reconocer la eficacia constitutiva de las estructuras simbólicas y anatomizar su doble impronta, sobre los complejos subjetivos de las disposiciones (categorías, habilidades y deseos) que conforman el habitus por una parte, y sobre la malla objetiva de las posiciones (distribuciones de recursos eficientes) que componen las instituciones, por el otro. El embrionario Filosofía de las formas simbólicas de Ernst Cassirer (1948) es la principal inspiración para el potente concepto de poder simbólico de Bourdieu que se encuentra en el epicentro y ápice de su obra, y sin embargo es a menudo ignorado por lecturas convencionales y usos de Bourdieu, osificado en el incompleto y redundante tríptico de "habitus, capital y campo" (Wacquant, 2017a). Debido a que el animal humano encuentra el universo físico no como una realidad brutal sino a través de los símbolos (materializados, en la taxonomía de Cassirer, como lenguaje, mito, religión, arte y ciencia), la ciencia más objetivista de la ciudad debe necesariamente dar espacio a los esquemas clasificatorios en competencia a través de los cuales los agentes establecen patrones y significados del mundo. $\mathrm{Y}$ dado que el mundo social siempre puede ser experimentado y construido a través de una pluralidad de puntos de vista, estos sistemas simbólicos en competencia constituyen muchas armas en la "lucha por producir e imponer la visión dominante del mundo" (Bourdieu [1982]1990, p. 159). Aplicado al espacio urbano, este principio implica prestar atención no solo a la fenomenología de la vida urbana como realidad vivida situada en sitios específicos, sino también a las palabras a través de las cuales se nombran personas, objetos, actividades y lugares de la ciudad, porque la categorización consecuente es un vector especialmente potente de conservación o transformación de la realidad, dada la concentración de las autoridades simbólicas (religiosas, políticas, legales, periodísticas, artísticas, académicas y científicas) en la metrópoli. ${ }^{22}$

En conjunto, estos principios alimentan una visión científica de la ciudad claramente divergente de aquellas impulsadas por el positivismo, el realismo y la hermenéutica, las alternativas epistemológicas que reinan transversalmente en las ciencias sociales. Esta postura ordena investigaciones centradas en una "construcción del objeto" ampliamente despierta y activa que evita tanto el formalismo vacío como el empirismo ciego para entrar en las especificidades de los casos históricos con el beneficio de una analítica generalizadora (Bourdieu, 2001). Junto con estos principios, uno puede destilar desde la práctica científica de Bourdieu tres advertencias generales que beneficiarán a los investigadores de la ciudad que deseen apropiarse de su trabajo, ya sea en letra o en espíritu. Primero, evitar la fetichización de los conceptos:

de Leibniz). Cabe señalar aquí que el primer libro de Cassirer (1902) fue una disección del pensamiento de Leibniz en su contexto científico.

22 El estampado material de la realidad urbana a través de su moldeado simbólico asume una forma paradigmática y paroxística con la estigmatización territorial, cuyos sitios y circuitos de producción, difusión y consumo impregnan la ciudad, a pesar de que se aferren a los distritos de perdición socio-moral en los límites y lo más bajo del espacio urbano (Wacquant, 2017b). 
Bourdieu es frecuentemente malinterpretado como un "teórico" cuando en realidad era un obstinado detractor de la "teorización conspicua”. Él interpretó la teoría no como el soberbio maestro, sino como el humilde servidor de la investigación empírica, y nunca avanzó en una sino a través del desarrollo de la otra (Bourdieu \& Wacquant, 1992, pp. 29-35 y passim). El correctivo para esta distorsión escolástica común, ejemplificado por muchos artículos recientemente publicados en [la revista] Progress in Human Geography, consiste en fundamentar la definición textual de los conceptos y prestar mucha atención a cómo Bourdieu los convierte en operaciones de investigación concretas para forjar sus objetos empíricos.

Segundo y relacionado a lo anterior, cuidado con la trampa retórica: innumerables autores pintan sus preguntas en el color de Bourdieu cuando en realidad las nociones de este último no juegan ningún papel en su análisis. Las palabras están ahí, pero los conceptos no. La prueba es que sus conclusiones y argumentos no son diferentes de si se hubieran derivado de cualquier enfoque alternativo (lo que generalmente era así). El concepto de campo es tal vez el más abusado de esta manera, como cuando es invocado como un sinónimo suave de dominio o arena, sin mostrar ninguna de las propiedades altamente distintivas que caracterizan un campo como tal según Bourdieu (diferenciación, autonomía, monopolización, organización quiasmática, efectos prismáticos, etc.). Al "hablar bourdiano" fuera de lugar, estos autores no solo confunden la retórica con la analítica; también obstruyen las ganancias teóricas y empíricas que ofrecería un despliegue eficaz de las herramientas de Bourdieu. Tales sondeos estériles degeneran fácilmente en un juego de palabras sin sentido, como lo ilustra la cómica multiplicación de un habitus torcidamente urbano en publicaciones recientes: el "habitus metropolitano", el "habitus suburbano", el "habitus de la gentrificación", el "habitus punto.com", sin mencionar el absurdo "mini-habitus" (quizás allanando el camino para el inminente nombramiento del nano-habitus), todos los cuales indican que sus inventores no entienden el significado y la composición básica del habitus (Wacquant, 2016). ${ }^{23}$

Tercero, no solo es posible sino generalmente deseable desacoplar los conceptos de Bourdieu entre sí, para asegurarse de que hay un beneficio real para su uso individual antes de que eventualmente se recombinen según sea necesario para estructurar y resolver el rompecabezas empírico en cuestión. La lectura teológica de las escrituras bourdianas estipulando que uno debe implementar sus nociones básicas juntas, está en contradicción directa con la pragmática de cualquier proyecto de investigación y choca con la manera en que el mismo Bourdieu las empleó. Por ejemplo, el sociólogo francés explota el habitus y el poder simbólico sin mencionar el campo en toda su obra argelina (Bourdieu, 1972, 1977, 1980, 2008), por la sencilla razón de que no existe ningún campo en las comunidades rurales de Cabilia. Esta estrategia

23 Es constitutiva de la metrópoli el contener una diversidad de poblaciones y categorías, un amplio abanico de condiciones sociales, y una pluralidad de microcosmos sociales limitados, cada uno fomentando esquemas de percepción y aprecio en competencia. Se deduce lógicamente que la metrópoli genera una gran diversidad de conjuntos de disposiciones en competencia (correspondientes a amplias clases de posiciones y trayectorias), y no un habitus unificado y singular, característico de la ciudad como tal. Hablar de un "habitus metropolitano (suburbano, etcétera)” es contagioso, pero de una palabrería bourdiana vacía. 
cautelosa es especialmente apropiada para aquellos investigadores que todavía están tanteando ir más allá de una comprensión elemental de la manera de pensar de Bourdieu: es mejor aplicar un concepto bien dentro de su propia esfera analítica que invocar cinco en proposiciones cruzadas o por mero efecto declamatorio.

Por ejemplo, la recapitulación de Nathan Marom (2014) de One Hundred Years of Spatial Distinction in Tel Aviv [Cien años de distinción espacial en Tel Aviv] ofrece un modelo de caso de un uso económico, eficiente y fructífero de Bourdieu que valida estas tres recomendaciones. Para dar sentido a la trayectoria de las oposiciones socioespaciales a lo largo de toda la vida de esta ciudad en disputa, Marom se centra en una sola operación, "la traducción del espacio social en el espacio físico". Dibuja elegantemente solo dos conceptos: el espacio social y el poder simbólico (cuyo dúo resulta ser el eje del pensamiento de Bourdieu); los acopla para romper con la problemática naturalizadora de la segregación heredada de la ecología urbana, así como para superar la ceguera de los enfoques de economía-política sobre la potencia performativa de las clasificaciones simbólicas y las luchas de clasificación. Bourdieu incita a Marom a formular una nueva pregunta, a historizar sus términos, y a desenterrar datos que le permitan documentar nuevas facetas empíricas del fenómeno $y$, en última instancia, a producir una interpretación original de los cambiantes principios de visión y división espacial de Tel-Aviv a través de escalas múltiples que otras perspectivas teóricas no podrían haber generado. Su artículo confirma además que, aunque cada uno de los siete conceptos principales que organizan el trabajo de Bourdieu (habitus, capital, espacio social, campo, poder simbólico, doxa y reflexividad epistémica) puede ser fructíferamente movilizado por los investigadores de constelaciones urbanas, el más potente y generativo del lote es indiscutiblemente el espacio social. No solo porque está anclado en una metáfora geográfica, sino porque es la "categoría madre" desde la cual fluyen los conceptos más restringidos de campo, cuerpo y aparato como tipos específicos de entornos en los que la acción social se arraiga y fluye (Wacquant 2017b) y porque es un "ajuste natural" para la ciudad como un medio que fomenta la incubación, diferenciación, proliferación y acumulación de formas competitivas de capital. ${ }^{24}$

\section{Aplicaciones: numerosos caminos en la ciudad bourdiana}

Habiendo establecido la pertinencia de Bourdieu para la investigación urbana y aclarado los principios que impulsan su trabajo, ahora llegamos a aplicaciones concretas. Los investigadores urbanos han ignorado sistemáticamente los distritos de riqueza, poder y privilegio por la sencilla razón de que plantean pocos "problemas sociales" a los administradores de la ciudad y porque los sociólogos han albergado desde hace mucho tiempo un enamoramiento romántico por categorías y territorios

24 De hecho, el espacio social es la única categoría que separa más decisivamente a Bourdieu de y llena un vacío abultado en el centro de todos los hilos existentes de la teoría urbana: la ecología y la etnografía estilo Chicago, la economía política, el urbanismo postcolonial, la teoría del ensamblaje, y la aproximación del nexo suelo-urbano (Storper y Scott 2016). 
socialmente subordinados. ${ }^{25}$ Nadie ha hecho más para tapar esa brecha que "las Pinçons" (como son conocidos por sus colegas franceses, así como para el amplio público que devora sus libros más vendidos) a lo largo de dos décadas dedicadas a investigar los mecanismos de producción y perpetuación de la desigualdad urbana en la elite (Pinçon \& Pinçon-Charlot, 1989, 1992, 1996, 2010).

Su artículo sobre "Class Power and Power over Space" ["El poder de clase y el poder sobre el espacio"] (Pinçon \& Pinçon-Charlot, 2017) sintetiza varios de sus libros para fundamentar la supremacía de la alta burguesía francesa (y la aristocracia restante) en su control del espacio y su capacidad de dar forma al lugar. Al extender el modelo de espacio social, formación de clases y práctica cultural de La distinción de Bourdieu (1979) para abarcar el espacio físico, revelan que el aislamiento electivo de la clase dominante en los barrios reservados es una base decisiva para su poder. Este aislamiento segregativo se ve reforzado por instituciones específicas de grupos, como bailes de sociedad y clubes sociales que trabajan junto a escuelas exclusivas para lograr un cierre rígido de clase. Pero, en este caso, el fundamento espacial de la dominación de clase se extiende más allá de la ciudad: además de sus hogares en París, las dinastías de clase alta poseen propiedades familiares (un castillo o una gran casa señorial) en el interior provincial, que ancla formas paternalistas de sociabilidad que las vinculan a la clase baja local a través de prácticas ritualizadas como las cacerías con perros —en las que los Pinçons participaron montando bicicletas de montaña durante su trabajo de campo (Pinçon \& Pinçon-Charlot, 1993 y 2005)—. Los espacios reservados por y para la alta burguesía son vectores importantes de la reproducción social debido a que moldean la subjetividad y entrenan herederos apropiados para salvaguardar y valorizar sus bienes heredados. Aquí Pinçon y Pinçon sugieren que los "efectos de barrio" que han obsesionado a los investigadores de la pobreza urbana son mucho más potentes y significativos en la parte superior que en el fondo del orden urbano, y al hacerlo indican cómo Bourdieu incita a una reorientación masiva del estudio del espacio, el lugar y la desigualdad.

Esta tríada analítica está en el centro de Urban Distinctions: Class, Culture, and Sociability in Porto [Distinciones urbanas: clase, cultura y sociabilidad en Oporto], en la que Virgílio Borges-Pereira (2017) se basa en su libro pionero Classes e culturas de classe de las famílias portuenses [Clases y culturas de clase de las familias portuenses],

25 Esta miopía tópica alimentada por el exotismo populista es ejemplificada por el elefantesco Urban Ethnography Reader [Compilado de Etnografía Urbana] recientemente publicado por Oxford University Press (Duneier, Kasinitz \& Murphy, 2014): sus casi 900 páginas no contienen un solo análisis de los espacios, instituciones y prácticas de la clase alta. Los términos “ayuntamiento” y "burguesía” no aparecen una sola vez en el libro; "clase alta" se menciona incidentalmente menos de una media docena de veces; 39 de los 52 capítulos se centran directamente en clases y etnias subalternas en distritos desposeídos; 27 asombrosos capítulos, más de la mitad de todo el volumen, están dedicados a los negros pobres de la "inner city" [áreas centrales] estadounidense. La metrópoli que emerge a través de estos lentes es una repleta de hombres negros descuidados, desviados y problemáticos (e incluso alimentadores de palomas), pero curiosamente carente de corporaciones, profesiones, políticos, fiscales, dinastías patricias, agentes inmobiliarios, burócratas, obispos, periodistas y científicos. Como es típico del género, este compendio masivo también contiene un solo capítulo y autor solitario situado fuera de los Estados Unidos y solo dos antropólogos, en una ignorancia dichosa de las ricas tradiciones de trabajo de campo urbano desarrollado en países extranjeros y por otras disciplinas. 
el cual extiende el modelo de espacio social y poder simbólico de La distinción de Bourdieu para investigar relaciones sociales y prácticas culturales en toda la gama de barrios de la ciudad portuguesa. Pereira combina la observación de campo con la metodología distintiva de Bourdieu del Análisis de Correspondencias Múltiples para proyectar una cartografía multicapas del espacio social de la ciudad sobre su disposición física. Encuentra que las diferencias en el volumen y la composición del capital entre los residentes de la ciudad subyacen en las relaciones modeladas entre la posición social, la disposición y el posicionamiento en diversos dominios de consumo cultural que van desde libros y televisión hasta vacaciones y ocio al aire libre, y actividades artísticas y religiosas. La triple agrupación vertical de "modalidades de estilo de vida" establecida por Bourdieu en la Francia de los ańos setenta, encapsulada por la tríada de "distinción, pretensión y necesidad", es obtenida para la ciudad portuguesa tres décadas después. Y de manera aún más notable, la oposición horizontal enraizada en la distribución quiasmática del capital económico y cultural emerge tanto entre la burguesía portuguesa como entre la pequeńa burguesía, mientras que el espíritu de resistencia de la clase obrera de la ciudad se ve erosionado por la atomización social y el individualismo negativo. Con este estudio de caso de Porto, Pereira ofrece una lúcida y analítica ejemplificación del mapeo mutuo del espacio social, simbólico y físico en una metrópoli y una resonante refutación empírica de la crítica común de que los modelos de Bourdieu reflejan las peculiaridades de la sociedad francesa ${ }^{26}$.

Como las Pinçons, Mike Savage y Laurie Hanquinet (2017) adoptan una visión desde arriba para dibujar un perfil comparativo de Londres y Bruselas ilustrando el surgimiento de Emerging Cultural Capital in the Metropolis [Capital cultural emergente en la metrópoli]. Esta es una historia de "efectos de grandes ciudades", en que se destaca la cristalización y acumulación de lo que, siguiendo a Ghassan Hage (1998), llaman "capital cultural cosmopolita", por oposición a las formas nacionales de autoridad cultural. Basados en grandes encuestas cuantitativas realizadas en Bélgica y el Reino Unido, Savage y Hanquinet describen el surgimiento de esta nueva especie de predilección y aptitud cultural como un desafío al dominio tradicional de la cultura intelectual, fundada en una estética kantiana contemplativa separada de cualquier sustrato físico en la medida en que erosiona la separación del arte y la vida "para valorizar la actividad, el compromiso y formas intensas de actividad cultural contemporánea”. Subrayan que este cambio cultural no señala la erosión de divisiones sociales, sino su reelaboración en torno a nuevos ejes embebidos en grandes centros urbanos donde las universidades de elite, complejos deportivos y barrios gentrificados atraen a profesionales jóvenes y fomentan nuevos patrones de consumo y entretenimiento. Al vincular el sustrato urbano con formas culturales cambiantes, Savage y Hanquinet movilizan a Bourdieu para revelar la geografía cambiante de la autoridad cultural en y a través de las ciudades. ${ }^{27}$

26 La respuesta propia de Bourdieu (1991) a esta preocupación es su "Introduction to a Japanesse Reading of 'Distinction'” [Introducción a una lectura japonesa de 'La distinción'].

27 Una advertencia analítica opera aquí: hay que tener cuidado con la proliferación incontrolada de las formas de capital que proviene de una interpretación sustancialmente errónea de la teoría de Bourdieu, que equipara el capital cultural con la cultura "intelectual" o con "bienes culturales de alto estatus”, y por eso confunde variación empírica con diferencia conceptual. Una capacidad, 
La contribución de Sylvie Tissot explota dos proyectos de investigación anteriores (Tissot, 2007 y 2011) para demostrar el valor del énfasis de Bourdieu en las luchas sobre nombramientos eficientes para analizar la rápida transformación del paisaje de las ciudades contemporáneas. El texto Categorizing Neighborhoods [Categorizando barrios] (Tissot, 2017) se extiende a través del Atlántico para esbozar la invención, difusión y los efectos de las etiquetas espaciales en la parte inferior y superior de la jerarquía metropolitana. En el lado francés, la categoría burocrática de quartier sensible (distrito "sensible" o "en riesgo") acuñado por los funcionarios del estado en París sirvió para estructurar y orientar la política de la ciudad después del final de la década de los ochenta, reformando eficazmente la periferia urbana al reformular la cuestión social del desempleo concentrado y la precariedad laboral en un tema de diseño espacial de la vivienda y acceso cívico. En el lado estadounidense, la noción de marketing de barrio "patrimonial" o "histórico", reclamada por asociaciones locales de residentes blancos recién llegados, aliados con agentes inmobiliarios y el municipio, se puso en marcha para facilitar y legitimar la gentrificación del South End de Boston bajo la bandera de la "diversidad". La ironía política es que los cambios urbanos perjudiciales para los residentes de clase baja fueron impulsados por una nueva retórica urbana promovida por profesionales y políticos estatales progresistas de ambos lados del Atlántico. El recordarnos que el vocabulario utilizado para dividir y representar la ciudad y sus componentes geográficos no es neutral ni vago, ${ }^{28}$ y el dilucidar las "condiciones sociales de producción y recepción" de esas "palabras que pueden hacer cosas" (Bourdieu, 1990, p. 328) son componentes esenciales de una sociología rigurosa de la desigualdad urbana.

Finalmente, en Heavy is the House [Pesada es la casa], Desmond (2017) conecta los primeros trabajos de Bourdieu sobre los subproletarios argelinos que emigran a la ciudad con su investigación tardía sobre la producción política del mercado de casas unifamiliares en Francia para hacer frente al creciente precio de alquileres que sufren los pobres en Estados Unidos, ya que sus ingresos cayeron mientras que el apoyo gubernamental a la vivienda de bajos ingresos desapareció. Desmond pone de relieve la deslumbrante desconexión entre la centralidad de la residencia en las estrategias de vida de los pobres y el persistente fracaso de la sociología urbana estadounidense para abordar la vivienda y reconocer la prevalencia de los desalojos y su papel en la reproducción de la pobreza extrema. Para remediar estas lagunas se requiere relocalizar la vivienda dentro de una corriente más amplia de luchas por espacio, trabajo,

un objeto o un título cultural dado nunca es capital cultural por sí mismo; se convierte en tal solo en relación con una arena particular de acción, en el que provoca la creencia colectiva, recibe valor y genera ganancias. Por ejemplo, el amor por la música clásica y el dominio de la historia del arte son capital cultural en el sistema escolar y en los círculos de clase media y alta, pero no en la esfera cotidiana de las familias obreras. La capacidad de entregar y soportar la violencia física es el capital cultural encarnado en el mundo criminal de la calle, pero no en una empresa o en un campus universitario. Léase la advertencia de Neveu (2013) contra la retórica "acumulación de capitales", lo que da como resultado un fugitivo "inventario sociológico sin pies ni cabeza".

28 Para críticas eficaces de la retórica urbana de "ciudades creativas", "barrios marginales", "villas” y "renacimiento", "patrimonio" y "diversidad", y (anti) gueto, y etiquetas parecidas para distritos desposeídos y menospreciados, ver respectivamente Peck (2005), Gilbert (2007), Barnes et al. (2006), Modan (2007) y Boyd (2008), y Wacquant, Slater y Pereira (2014). 
dinero y poder que moldean la metrópoli. Desmond astutamente aboga por "traer a los terratenientes de vuelta" para trazar sus transacciones ascendentes con los prestamistas, corredores y asociaciones inmobiliarias, así como los cambiantes estándares materiales y morales que guían sus relaciones descendentes con los inquilinos (como se muestra en una etnografía relacionada de un desalojo en Milwaukee; Desmond, 2016). También recomienda seguir las conexiones entre el mundo diferenciado de los terratenientes y el campo burocrático en los niveles local, regional y nacional y cómo estos impactan la producción, asignación y estabilidad de la vivienda en el nivel más bajo del orden metropolitano. En resumen, elevar el estatus de la vivienda como un objeto empírico requiere renovar nuestro modelo teórico de la ciudad como producto, sitio y objetivo de clasificación y estratificación.

Cada uno de los artículos reunidos en la rúbrica "Llevando a Bourdieu a la ciudad" 29 es por sí mismo una rica y estimulante investigación dentro de los elementos y determinantes de una porción de la vida urbana. Juntos, demuestran la flexibilidad y productividad de los conceptos claves, movimientos metodológicos y punteros empíricos de Bourdieu, así como una aproximada división analítica del trabajo que se obtiene entre ellos. Estos artículos sugieren cómo Bourdieu puede estimular, enriquecer y reorientar la investigación urbana, e incluso disolverla en una más amplia ciencia social topológica capaz de abarcar la ciudad en una analítica más extensa de las relaciones dinámicas entre división simbólica, espacio social $y$ entorno construido. Bourdieu no solo ańade una nueva serie de nociones poderosas y flexibles (habitus, capital, espacio social, campo, doxa, poder simbólico y reflexividad) a la panoplia de perspectivas teóricas establecidas: abre un camino para reconceptualizar lo urbano como dominio de acumulación, diferenciación y disputa de múltiples formas de capital, lo que efectivamente hace de la ciudad un terreno central y una recompensa para las luchas históricas.

\section{Agradecimientos}

Quisiera dar las gracias a los participantes en el seminario de York Research llamado "Llevando a Bourdieu a la ciudad", y primero entre ellos a Mike Savage, quien asumió su organización y la llevó a su realización intelectual; a Simon Parker y Liza Weinstein por acorralar los artículos para este número especial y a los editores de IJURR por su ilimitada paciencia y ecuanimidad. Mis agradecimientos también a Megan Comfort, Chris Herring, Franck Poupeau y David Showalter por sus cuidadosos comentarios y sugerencias en versiones anteriores de este artículo.

29 Nota de la traducción: aquí el autor se refiere a los artículos reunidos en los números especiales de la revista International Journal of Urban and Regional Research (IJURR), en prensa 2017. 


\section{Referencias bibliográficas}

Bachelard, Gaston. 1938. La Formation de l'esprit scientifique. Contribution à une psychanalyse de la connaissance objective. Paris: Vrin, 1999. (Español: 2007. La formación del espiritu cientifico. Ciudad de México, México: Siglo xxi).

Barnes, Kendall, Gordon Waitt, Nicholas Gill and Chris Gibson. 2006. "Community and Nostalgia in Urban Revitalisation: A Critique of 'Urban Village' and 'Creative Class' Strategies as Remedies for Social 'Problems'.' Australian Geographer 37, no 3: 335-354.

Bourdieu Pierre. 1958. Sociologie de l'Algérie. Paris: Presses Universitaires de France (modified English tr. The Algerians, Boston: Beacon Press, 1962). (Español: 2006. Sociología de Argelia y Tres estudios de etnología cabilia. Madrid, Espańa: Centro de Investigaciones Sociológicas.)

Bourdieu Pierre. 1962. “Célibat et condition paysanne.” Études rurales 5-6 (April): 32-136. English: abridged as Part 1 of The Ball of Bachelors: The Crisis of the Peasant Society in Béarn (Cambridge: Polity Press, [2002] 2008), pp. 7-130. (Español: 2004. El baile de los solteros. Barcelona, España: Editorial Anagrama.)

Bourdieu Pierre, Alain Darbel, Jean-Pierre Rivet and Claude Seibel. 1963. Travail et travailleurs en Algérie. Paris and the Hague: Mouton. (Versión abreviada y corregida en español: 2013. Algeria 60: Estructuras económicas y estructuras temporales. Buenos Aires, Argentina: Siglo XxI Editores.)

Bourdieu Pierre and Abdelmalek Sayad. 1964a. Le Déracinement. La crise de l'agriculture traditionnelle en Algérie. Paris: Minuit. (Español: 2017. El desarraigo: La violencia del capitalismo en una sociedad rural. Buenos Aires, Argentina: Siglo Xxi Editores.)

Bourdieu, Pierre, Jean-Claude Chamboredon and Jean-Claude Passeron. 1968. Le Métier de sociologue. Préalables épistémologiques. Paris and The Hague: Mouton (English: The Craft of Sociology, New York, Walter De Gruyter, 1991). (Español: 2013. El oficio del sociólogo: Presupuestos epistemológicos. Madrid, España: Siglo XxI Editores).

Bourdieu, Pierre 1972. Esquisse d'une théorie de la pratique, précédée de trois essais d'ethnologie kabyle. Geneva: Droz. English modified tr. Outline of a Theory of Practice (Cambrige: Cambridge University Press, 1977). (Español: 2012. Bosquejo de una teoría de la práctica. Buenos Aires, Argentina: Prometeo Libros).

Bourdieu Pierre. 1977. Algérie 60. Structures temporelles et structures sociales. Paris: Minuit. (English: Algeria 1960, Cambridge, uk: Cambridge University Press, 1979). (Español: 2013. Algeria 60: Estructuras económicas y estructuras temporales. Buenos Aires, Argentina: Siglo XxI Editores.)

Bourdieu Pierre. 1979. La Distinction. Critique sociale du jugement. Paris: Minuit. (English: Distinction: A Social Critique of the Judgement of Taste, Cambridge, Ma: Harvard University Press, 1984). (Español: 1988. La distinción: Criterios y bases sociales del gusto. Ciudad de México, México: Taurus).

Bourdieu Pierre. 1980. Le Sens pratique. Paris: Minuit. English: The Logic of Practice (Cambridge, UK: Polity Press, 1990). (Español: 2008. El sentido práctico. Madrid, España: Siglo XXI Editores.)

Bourdieu, Pierre. [1982] 1990. Language and Symbolic Power. Cambridge: Harvard University Press. (Versión abreviada en español: 2008. ¿Qué significa hablar? Economía de los intercambios lingüisticos. Madrid, España: Akal.) 
Bourdieu Pierre. 1989. La Noblesse d'État. Grandes écoles et esprit de corps. Paris: Minuit. English: The State Nobility: Elite Schools in the Field of Power (Cambridge, un: Polity Press, 1996). (Español: 2013. La nobleza de Estado: Educación de elite y espiritu de cuerpo. Buenos Aires, Argentina: Siglo xxI Editores.)

Bourdieu, Pierre. 1991. "First lecture. Social Space and Symbolic Space: Introduction to a Japanese Reading of 'Distinction'." Poetics Today 12, no. 4: 627-638. (Español: 1997. Espacio social y espacio simbólico: Introducción a la lectura japonesa de La Distinción, en I. Jiménez (Ed.) Capital cultural, escuela y espacio social (pp. 10-18). Ciudad de México, México: Siglo xxi Editores).

Bourdieu Pierre. [1991] 2017. "Social Space, Symbolic Space and Appropriated Physical Space." Paper presented at the Russell Sage/MsH Conference on "Poverty, Immigration and Urban Marginality in Advanced Societies," Paris, Maison des Science de l'Homme, 10-11 May. English: "Social Space and the Genesis of Appropriated Physical Space." International Journal of Urban and Regional Research, this issue.

Bourdieu, Pierre and Wacquant, Loïc. 1992. An Invitation to Reflexive Sociology. Chicago: The University of Chicago Press; Cambridge: Polity Press. (Español: 2008. Una invitación a la sociología reflexiva. Buenos Aires, Argentina: Siglo xxi Editores).

Bourdieu, Pierre. 1993. Effets de lieux. In Pierre Bourdieu et al., La Misère du monde. Paris: Seuil, pp. 123-129. (Español: 1999. Efectos de lugar, en P. Bourdieu et al. (Eds.) La miseria del mundo (pp. 119-124). Buenos Aires, Argentina: Fondo de Cultura Económica).

Bourdieu Pierre et al. 1993. La Misère du monde. Paris: Seuil (English tr. The Weight of the World: Social Suffering in Contemporary Society, Cambridge: Polity Press, 1999). (Español: 1999. La miseria del mundo. Buenos Aires, Argentina: Fondo de Cultura Económica).

Bourdieu, Pierre. 1997. Méditations pascaliennes. Paris: Seuil. English: Pascalian Meditations (Cambridge, uk: Polity Press, 2000). (Español: 1999. Meditaciones pascalianas. Madrid, España: Anagrama).

Bourdieu, Pierre. [2000]. 2011. "With Weber, Against Weber." Pp. 111-124 in The Legacy of Pierre Bourdieu: Critical Essays. Edited by Simon Susen \& Bryan S. Turner. London: Anthem Press.

Bourdieu, Pierre. 2001. Science and la science et réflexivité. Paris: Raisons d'agir Éditions (English: Science of Science and Reflexivity, Cambridge, Polity Press, 2006). (Español: 1999. El oficio del científico: Ciencia de la ciencia y reflexividad. Barcelona, España: Editorial Anagrama).

Bourdieu, Pierre. 2002. Le Bal des célibataires. Crise de la société paysanne en Béarn. Paris: Seuil. (Español: 2004. El baile de los solteros. Barcelona, España: Editorial Anagrama.)

Bourdieu, Pierre. 2008. Esquisses algériennes. Paris: Seuil (English: Algerian Sketches, Cambridge: Polity Press, 2013).

Boyd, Michelle R. 2008. Jim Crow Nostalgia: Reconstructing Race in Bronzeville. Minneapolis: University of Minnesota Press.

Cassirer, Ernst. 1902. Leibniz' System in seinen wissenschaftlichen Grundlagen. Marburg: Elwert.

Cassirer, Ernst. 1944. An Essay on Man: An Introduction to a Philosophy of Human Culture. New Haven: Yale University Press.

Cresswell, Tim. 2002. "Bourdieu's Geographies." Environment and Planning D: Society and Space 20: 379-382. 
Desmond, Matthew. 2012. "Eviction and the Reproduction of Urban Poverty." American Journal of Sociology 118, no. 1 (May): 88-133.

Desmond, Matthew. 2016. Evicted: Poverty and Profit in the American City. New York: Crown.

Desmond, Matthew. 2017. "Heavy is the House: Rent Burden among the American Urban Poor." International Journal of Urban and Regional Studies, this issue.

De Risi, Vincenzo. 2007. Geometry and Monadology: Leibniz's Analysis Situs and Philosophy of Space. Basel: Birkhäuser.

Duneier, Mitchell, Philip Kasinitz, and Alexandra Murphy, eds. The Urban Ethnography Reader. New York: Oxford University Press.

Durkheim, Émile, and Marcel Mauss. 1901. "De quelques formes primitives de classification: contribution à l'étude des représentations collectives." L'Année sociologique 6: 1-72. English: Primitive classification (Chicago: University of Chicago Press, 1963). (Español: 1996. Clasificaciones primitivas ( $Y$ otros ensayos de antropología positiva). Barcelona, España: Ariel).

Fogle, Nikolaus. 2011. The Spatial Logic of Social Struggle: A Bourdieuian Topology. Lexington, MA: Lexington.

Gilbert, Alan. 2007. "The Return of the Slum: Does Language Matter?” International Journal of Urban and Regional Research 31, no. 4: 697-713.

Hage, Ghassan. 1998. White Nation: Fantasies of White Supremacy in a Multicultural Society. Sydney: Pluto.

Harding, Alan and Talja Blokland. 2014. Urban Theory: A Critical Introduction to Power, Cities and Urbanism in the $21^{\text {st }}$ Century. London: Sage.

Jazouli, Adil. 1992. Les Années banlieues. Paris: Seuil.

Lebaron, Frédéric and Brigitte LeRoux (eds.). 2015. La Méthodologie de Pierre Bourdieu en action. Espace culturel, espace social et analyse des données. Paris: Dunod.

Lippuner, Roland. 2012. "Pierre Bourdieu," in Eckard (ed.), Handbuch Stadtsoziologie. Berlin: vsA Verlag.

Marom, Nathan. 2014. "Relating a City's History and Geography With Bourdieu: One Hundred Years of Spatial Distinction In Tel Aviv." International Journal of Urban and Regional Research 38, no. 4: 1344-1362.

Modan, Gabriella Gahlia. 2007. TurfWars: Discourse, Diversity, and the Politics of Place. Malden, MA: Blackwell.

Neveu, Érik. 2013. "Les sciences sociales doivent-elles accumuler les capitaux?" Revue française de science politique 63, no. 2: 337-358.

Painter, Joe. 2000. "Pierre Bourdieu." In Mike Crang and Nigel Thrift (eds.). Thinking Space. London: Routledge, pp. 239-259.

Pereira, Virgílio Borges. 2005. Classes e culturas de classe das famílias portuenses. Porto: Afrontamento.

Pereira, Virgílio Borges. 2017. "Urban Distinctions: Class, Culture, and Sociability in Porto." International Journal of Urban and Regional Studies, this issue.

Pinçon, Michel and Monique Pinçon-Charlot. 1989. Dans les beaux quartiers. Seuil, Paris.

Pinçon, Michel and Monique Pinçon-Charlot. 1992. Quartiers bourgeois, quartiers d'affaires. Payot, Paris.

Pinçon, Michel and Monique Pinçon-Charlot. 1993. La Chasse à courre. Ses rites et ses enjeux. Paris: Payot. 
Pinçon, Michel and Monique Pinçon-Charlot. 1996. Grandes fortunes. Dynasties familiales et formes de richesse en France. Paris : Payot. (English tr, Grand Fortunes. Dynasties and Forms of Wealth in France, New York, Algora, 1998.

Michel Pinçon and Monique Pinçon-Charlot. 2005. Voyage en grande bourgeoisie. Journal d'enquête. Paris: Puf.

Pinçon, Michel and Monique Pinçon-Charlot. 2010. Les Ghettos du gotha ( $2^{\text {nd }}$ edition; $1^{\text {st }}$ edition 2007). Paris: Points/Seuil.

Pinçon, Michel and Monique Pinçon-Charlot. 2017. "Class Power and Power over Space: How the Bourgeoisie Reproduces Itself in the City." International Journal of Urban and Regional Studies, this issue.

Peck, Jamie. 2005. "Struggling with the Creative Class." International journal of urban and regional research 29, no. 4: 740-770.

Rheinberger. Hans-Jörg, 2010. On Historicizing Epistemology: An Essay. Stanford: Stanford University Press.

Ripoll, Fabrice. 2013. "Quelle dimension spatiale des structures sociales chez Bourdieu? Localisations résidentielles et jeux d'échelles dans La Distinction." Pp. 365-377 in Philippe Coulangeon and Julien Duval (eds.), Trente ans après "La Distinction"de Pierre Bourdieu. Paris: La Découverte.

Rosenlund, Lennart. 2009. Exploring the City with Bourdieu: Applying Pierre Bourdieu's Theories and Methods to Study the Community. Berlin: vdm Publishing.

Savage, Mike. 2011. "The Lost Sociology of Pierre Bourdieu." Pp. 511-520 in The New Blackwell Companion to the City. Edited by Gary Bridge and Sophie Watson. Cambridge: Blackwell.

Savage, Mike and Laurie Hanquinet. 2017. "Emerging Cultural Capital in the Metropolis: Profiling London and Brussels." International Journal of Urban and Regional Studies, this issue.

Storper, Michael, and Allen J. Scott. 2016. "Current Debates in Urban Theory: A Critical Assessment." Urban Studies 53, no. 6: 114-1136.

Tissot, Sylvie. 2007. L'État et les quartiers. Enquête sur une catégorie de l'action publique. Paris: Seuil.

Tissot, Sylvie. 2011. De bons voisins. Enquête dans un quartier de la bourgeoisie progressiste. Paris: Raisons d'agir éditions.

Tissot, Sylvie. 2017. "Categorizing Neighborhoods: The Invention of 'Sensitive Areas' in France and 'Heritage Districts' in the United States." International Journal of Urban and Regional Studies, this issue.

Wacquant, Loïc. 2002. "Scrutinizing the Street: Poverty, Morality, and the Pitfalls of Urban Ethnography." American Journal of Sociology 107-6 (May): 1468-1532.

Wacquant, Loïc. 2004. "Following Pierre Bourdieu into the Field." Ethnography 5, no. 4 (December): 387-414. (Espańol: "Adentrarse en el campo con Bourdieu." Minerva. Círculo de Bellas Letras, 20, Fall 2012, pp. 48-58.)

Wacquant, Loïc. 2008. Urban Outcasts: A Comparative Sociology of Advanced Marginality. Cambridge: Polity Press. (Español: Los Condenados de la ciudad. Gueto, periferias, Estado. Buenos Aires, Mexico, Madrid: Siglo 21, 2007.) 
Wacquant, Loïc. 2013. "Symbolic Power and Group-Making: On Bourdieu’s Reframing of Class." Journal of Classical Sociology 13, no. 2 (May): 274-291. (Español: "Poder simbólico y fabricación de grupos: Cómo Bourdieu reformula la cuestión de las clases", Herramientas (Buenos Aires), 52, March 2013, pp. 117-138).

Wacquant, Loïc. 2014. "Marginality, Ethnicity and Penality in the Neoliberal City: An Analytic Cartography." Ethnic \& Racial Studies 37, no. 10 (symposium with responses from Andy Clarno, Michael Dawson, Matt Desmond, Amy Lerman, Mara Loveman, Douglas Massey, Dorothy Roberts, Robert Sampson, William Julius Wilson, Andreas Wimmer): 1687-1711. (Español: "Marginalidad, etnicidad y penalidad en la ciudad neoliberal: una cartografía analítica”, en Claudia Corol et al. (eds.), Tiempos violentos. Barbarie y decadencia civilizatoria, Buenos Aires, Ediciones, 2014, pp. 177-212; también en Mayarí Castillo Gallardo y Claudia Maldonado Graus (eds.), Desigualdades. Tolerancia, legitimación y conflicto en las sociedades latinoamericanas (Santiago de Chile, RIL Editores, 2014), pp. 183-214).

Wacquant, Loïc. 2015. "Revisiting Territories of Relegation: Class, Ethnicity and the State in the Making of Advanced Marginality." Urban Studies Journal 53, no. 6 (symposium with responses by Nicole Marwell, Janos Ladanyí, Troels Schultz Larsen, Orlando Patterson, and Emma Shaw Crane): 1077-1088. (Español: "Repensando los condenados de la ciudad: clase, etnicidad y Estado en la producción de marginalidad", Revista de Ciencias Sociales (Buenos Aires), Summer 2013, pp. 10-19).

Wacquant, Loïc. 2016. "A Concise Genealogy and Anatomy of Habitus." The Sociological Review 64, no. 1: 64-72.

Wacquant, Loïc. 2017a. "Practice and Symbolic Power in Bourdieu: The View from Berkeley." Journal of Classical Sociology 17, no. 1 (February): in press. (Español: "Práctica y poder simbólico en Bourdieu: La visión desde Berkeley”, en prensa, Herramientas).

Wacquant, Loïc. 2017b. The Two Faces of the Ghetto. Cambridge: Polity Press.

Wacquant, Loïc, Tom Slater and Virgílio Pereira. 2014. "Territorial Stigmatization in Action." Special issue of Environment \& Planning A 46, no. 6 (June): 1270-1280. (Español: "Estigmatización territorial en acción”, Revista INVI (Santiago de Chile), 29, Fall 2014, pp. 219-240).

Weber, Max. 1958. From Max Weber: Essays in Sociology. Edited by H. H. Gerth an C.-Wright Mills. New York: Oxford University Press, new ed. (Español: 1972. Ensayos de sociología contemporánea. Barcelona, España: Ediciones Martínez Roca).

Webster, Helena, 2010. Bourdieu for Architects. London: Routledge.

Weik, Elke. 2010. "Research note: Bourdieu and Leibniz: Mediated Dualisms." The Sociological Review 58, no. 3: 486-496.

Wirth, Louis. 1938. "Urbanism as A Way of Life." American Journal of Sociology 44, no. 1 (July): 1-24. (Espańol: 1962. El urbanismo como modo de vida. Buenos Aires, Argentina: Ediciones 3). 